\title{
A summary of the study on talent training under the visual threshold of Intelligent Tourism
}

\author{
Xuemei Zou ${ }^{1,2, a,{ }^{*}}$ Chaoyang Fang ${ }^{1, b}$
}

${ }^{1}$ College of geography and environment, Jiangxi Normal University,Nanchang,Jiangxi,China 2Jiangxi Industrial Trade Career Technical College,Nanchang,Jiangxi,China

\author{
aemail, xuemeizou@foxmail.com \\ bemail, 1036213442@qq.com \\ ${ }^{*}$ Corresponding author
}

Keywords: Intelligent Tourism, personnel training, Training mode

\begin{abstract}
The age of Intelligent Tourism is the deep integration of tourism and information technology development, it is a new stage of tourism development, and the cultivation of intelligent tourism talents is the key to ensure the smooth development of intelligent tourism, and also the focus and core of the further development of intelligent tourism. This article is mainly through the literature of the training of Intelligent Tourism Talents in CNKI as the study object, in-depth analysis, and concludes that the study results of the training of Intelligent Tourism Talents in China are based on industry guidance. It includes the construction of the training mode of intelligent tourism talents, the reform of the professional curriculum system, the innovation of the model of school enterprise cooperation in the new age of wisdom and the demand and influence of the talents in the age of intelligent tourism. Through the analysis of the attention and characteristics of the study on the training of Intelligent Tourism Talents in China. It is a great practical and theoretical significance to further guide our study on Intelligent Tourism Talents and to promote the in-depth and comprehensive development of Intelligent Tourism.
\end{abstract}

\section{智慧旅游视阈下旅游人才培养研究综述}

\author{
邹雪梅 ${ }^{1,2, a,{ }^{*}}$ ，方朝阳 ${ }^{1, b}$ \\ 1江西师范大学地理与环境学院, 南昌, 江西, 中国 \\ 2江西工业贸易职业技术学院, 南昌, 江西, 中国 \\ aemail, xuemeizou@foxmail.com \\ bemail, 1036213442@qq.com
}

通讯作者

关键词: 智慧旅游; 人才培养; 培养模式

中文摘要. 智慧旅游时代是旅游业态与信息技术的深度融合阶段, 是旅游发展的全新阶段, 而智慧旅游人才的培养则是保障智慧旅游得以顺利开展的关键，是智慧旅游时代进一步发展 的焦点和核心。本文主要是通过对中国知网中智慧旅游人才培养方面的文献作为研究对象, 深入分析, 总结出目前我国智慧旅游人才培养的研究成果以行业指导为主, 涉及到智慧旅游 人才培养模式的构建、专业课程体系的改革、校企合作模式的创新以及智慧旅游时代对人才 的需求及影响等方面。通过分析我国智慧旅游人才培养方面研究的关注点和特征, 对进一步 指导我们进行智慧旅游人才培养, 促进智慧旅游的深入和全面发展, 具有重要的理论和现实 意义。 


\section{1. 引言}

智慧旅游人才是智慧旅游活动的关键和保障, 而我国对于智慧旅游人才培养的研究起步 较晚, 于 2013 年才有第一篇关于智慧旅游人才培养的文献, 但随着智慧旅游热的高温蒸腾, 智慧旅游人才的关注也进入到快速发展阶段, 近年来研究成果不断增多, 研究内容越来越细 化。本文主要是通过中国知网 (CNKI) 上整理的智慧旅游人才培养的文献作为主要研究对象, 通过分析和整理了解到智慧旅游人才培养研究的焦点和热点主要是大的行业指导的定性研 究, 此外也有部分学者以具体的地市或院校作为应用研究, 但整个研究角度基本上以院校旅 游专业培养模式为主, 很少涉及行业上具体从业人员的人才再培养, 且都以大的培养模式的 研究居多, 缺乏具体的培养过程和培养细节的研究, 研究深度不够, 方法较为单一。

\section{2. 智慧旅游人才培养文献分析}

\section{1 文献总数}

从中国知网（CNKI）上对 “智慧旅游人才培养” 作为主题进行搜索发现，对于该领域的 研究时间比较晚, 从2013年至今共计文献数量166个, 旅游的研究文献进行检索和分析 (检索 时间: 2018 年 3 月 5 日), 以 “智慧旅游人才培养” 为关键词检索 “篇名” ，共检索到文献总数 32篇, 并且文献类型均为期刊; 以 “智慧旅游人才培养” 为关键词检索 “主题” , 共检索到 文献79篇 (其中期刊文献 71 篇，硕士论文 6 篇，博士论文 1 篇，报纸文章 1 篇)；以 “智慧旅游人 才培养” 为关键词检索 “全文” , 共检索到文献总数 778 篇 (其中期刊文献417篇, 硕博士论文 218篇，报纸文章54篇，会议论8篇），具体分布如表1所示：

表1＼cjkstart智慧旅游人才培养研究文献分布（检索时间2018年3月5日）

\begin{tabular}{c|ccc}
\multicolumn{1}{c}{ 搜索分类 } & 按篇名 & 按主题 & 按全文 \\
\hline 文献总篇数 & 32 & 79 & 778 \\
期刊文献篇数 & 32 & 71 & 418 \\
硕博论文篇数 & 0 & 7 & 218 \\
会议论文篇数 & 0 & 0 & 54 \\
报纸文章篇数 & 0 & 1 & 96 \\
\hline
\end{tabular}

\section{2 文献分布特点}

通过检索和分析中国知网 (CNKI) 有关智慧旅游人才培养方面文献的析出指数，以 “智 慧旅游人才培养” 为关键词进行全文分析, 发现该领域的研究在发表时间、研究学科与层次、 期刊分布、研究机构等方面呈现以下特点。

2.2.1 发表时间

表2 智慧旅游人才培养研究文献发表年份数量分布

\begin{tabular}{|c|c|c|c|c|c|c|c|c|}
\hline 年度 & 2011 & 2012 & 2013 & 2014 & 2015 & 2016 & 2017 & 2018 \\
\hline 文献数 (篇) & 1 & 21 & 40 & 87 & 144 & 215 & 216 & 11 \\
\hline
\end{tabular}

我国最早对智慧旅游的研究始于 2010 年, 从发表时间可以看出, 关于智慧旅游人才培养 方面的研究稍晚于智慧旅游的研究, 2011年有1篇, 但实际上2011年的这篇文献题目是《智慧 城市评价指标体系研究》, 文章只是提到智慧旅游人才培养对于智慧城市建设来说具有重要 意义, 而真正把智慧旅游人才培养作为论题, 进行系统智慧旅游人才培养模式的研究始于 2013 年, 可以说智慧旅游人才培养的真正研究起步晚, 远落后于智慧旅游具体技术架构和平台开 发的研究。但从文献整体数量来说, 近几年的增速比较明显, 增量较多, 这与智慧旅游的快 速发展的节奏是相吻合的, 未来关于智慧旅游人才培养方面的研究将会有更多的关注。 


\subsection{2 研究文献情况分析}

由于智慧旅游人才培养方面的研究时间较短, 单独以智慧旅游人才培养为篇名进行研究 的文献数量较少, 不具有很好的统计分析意义, 因此表 3 主要是通过中国知网 (CNKI) 进行全 文检索，能够更全面的了解智慧旅游人才研究的文献分布情况。

表3 智慧旅游人才培养研究文献分布特点

\begin{tabular}{|c|c|c|c|c|c|c|}
\hline 排序 & 研究学科 & 研究层次 & 文献分布 & 研究机构 & 硕博士论文 & 关键词 \\
\hline 1 & 旅游学科 (551) & $\begin{array}{l}\text { 基础研究 } \\
\text { (社科) (265) }\end{array}$ & $\begin{array}{c}\text { 旅游纵览 } \\
\text { (28) }\end{array}$ & $\begin{array}{c}\text { 辽宁师范大 } \\
\text { 学 (15) }\end{array}$ & $\begin{array}{c}\text { 南昌大学 } \\
\text { (9) }\end{array}$ & $\begin{array}{c}\text { 智慧旅游 } \\
\text { (132) }\end{array}$ \\
\hline 2 & 高等教育 (102) & $\begin{array}{c}\text { 行业指导 } \\
\text { (科) (251 } \\
\text { ) }\end{array}$ & $\begin{array}{l}\text { 中国旅游 } \\
\text { 报 (18) }\end{array}$ & $\begin{array}{c}\text { 洛阳师范学 } \\
\text { 院 (14) }\end{array}$ & $\begin{array}{c}\text { 云南大学 } \\
\text { (6) }\end{array}$ & $\begin{array}{c}\text { 人才培养 } \\
(49)\end{array}$ \\
\hline 3 & 职业教育 (101) & $\begin{array}{l}\text { 政策研究 } \\
\text { (社科) (117 }\end{array}$ & $\begin{array}{c}\text { 云南大学 } \\
\text { 学位论文 (6) }\end{array}$ & $\begin{array}{c}\text { 沈阳师 } \\
\text { 范大学 } \\
(10)\end{array}$ & $\begin{array}{c}\text { 燕山大学 } \\
\text { (6) }\end{array}$ & $\begin{array}{c}\text { 智慧城市 } \\
\text { (34) }\end{array}$ \\
\hline 4 & $\begin{array}{c}\text { 信息经济与邮 } \\
\text { 政经济 (73) }\end{array}$ & $\begin{array}{c}\text { 职业指导 } \\
\text { (社科) (39) }\end{array}$ & $\begin{array}{c}\text { 南昌大学 } \\
\text { 学位论文 (9) }\end{array}$ & 燕山大学 (10 & $\begin{array}{l}\text { 西北师范 } \\
\text { 大学 (4) }\end{array}$ & $\begin{array}{c}\text { 旅游管理 } \\
\text { (33) }\end{array}$ \\
\hline 5 & $\begin{array}{c}\text { 经济体制改革 } \\
(42)\end{array}$ & 高等教育 (36) & $\begin{array}{c}\text { 燕山大学 } \\
\text { 学位论文 (6) }\end{array}$ & $\begin{array}{l}\text { 桂林理工大 } \\
\text { 学 (10) }\end{array}$ & $\begin{array}{c}\text { 扬州大学 } \\
\text { (4) }\end{array}$ & $\begin{array}{c}\text { 旅游业 } \\
\text { (28) }\end{array}$ \\
\hline 6 & 贸易经济 (42) & $\begin{array}{c}\text { 基础教育与中 } \\
\text { 等职业教育 } \\
\text { (25) }\end{array}$ & $\begin{array}{c}\text { 中国商贸 } \\
(6)\end{array}$ & 南昌大学 (9 & $\begin{array}{c}\text { 河南大学 } \\
\text { (4) }\end{array}$ & $\begin{array}{l}\text { 旅游管理 } \\
\text { 专业（24） }\end{array}$ \\
\hline 7 & $\begin{array}{c}\text { 宏观经济管理 } \\
\text { 与可持续发展 } \\
(38)\end{array}$ & $\begin{array}{l}\text { 工程技术 } \\
\text { (自科) (9) }\end{array}$ & $\begin{array}{l}\text { 现代商贸 } \\
\text { 工业（6） }\end{array}$ & $\begin{array}{l}\text { 广西师范 } \\
\text { 大学 (9) }\end{array}$ & $\begin{array}{c}\text { 华侨大学 } \\
\text { (4) }\end{array}$ & 对策（21） \\
\hline 8 & 文化 (29) & $\begin{array}{l}\text { 业实用技术 } \\
\text { (自科) (2) }\end{array}$ & 特区经济（5） & 河南大学 (8) & $\begin{array}{c}\text { 福建农 } \\
\text { 林大学 } \\
\text { (4) }\end{array}$ & $\begin{array}{c}\text { 旅游产业 } \\
\text { (19) }\end{array}$ \\
\hline 9 & $\begin{array}{c}\text { 中国政治与国 } \\
\text { 际政治 (27) }\end{array}$ & $\begin{array}{c}\text { 基础与应用基 } \\
\text { 础研究 } \\
\text { (自科) (2) }\end{array}$ & $\begin{array}{c}\text { 长春师范 } \\
\text { 学院学报 (5) }\end{array}$ & $\begin{array}{c}\text { 南京旅游职 } \\
\text { 业学院 (8) }\end{array}$ & $\begin{array}{c}\text { 大连理 } \\
\text { 工大学 } \\
\text { (4) }\end{array}$ & $\begin{array}{c}\text { 乡村旅游 } \\
\text { (18) }\end{array}$ \\
\hline 10 & 农业经济 (23) & $\begin{array}{c}\text { 行业技术指导 } \\
\text { (自科) (2) }\end{array}$ & $\begin{array}{l}\text { 改革与开 } \\
\text { 放 (5) }\end{array}$ & 云南大学 (8) & $\begin{array}{c}\text { 广西大学 } \\
\text { (4) }\end{array}$ & $\begin{array}{c}\text { 旅游专业 } \\
\text { (18) }\end{array}$ \\
\hline
\end{tabular}

2.2.2.1 研究学科

通过表3可以看出, 按照学科分类, 在 778 篇智慧旅游人才培养方面的研究文献中, 排在 前10位的学科分别为: 旅游学科 (551), 高等教育 (102), 职业教育 (101), 信息经济与邮政经 济 (73) , 经济体制改革 (42), 贸易经济 (42), 宏观经济管理与可持续发展 (38), 文化 (29), 中国政治与国际政治 (27), 农业经济 (23)。这说明智慧旅游人才培养方面的研究的学科背景 以旅游学科和信息通信技术为主, 达 $70 \%$, 其次为高等教育和职业教育, 占 $26 \%$, 只有不超过 $4 \%$ 的研究零星的分布在经济类、文化类学科中。

2.2.2.2 研究层次

按照研究层次分类, 在778篇智慧旅游人才培养方面的研究文献中, 排名前十的研究层次 先后分别为: 社科基础研究 (265, 占比 $34.1 \%$ ), 社科行业指导 (251, 占比 $32.3 \%$ ), 社科政 策研究 $(117,15 \%)$ ，社科职业指导 (39，5\%)，高等教育（36，4.6\%），基础教育与中等 职业教育 $(25,3.2 \%)$ ，排名 $6-10$ 位的研究层次的文献数均在个位数以下，且总共占比 $2 \%$ 。 这说明智慧旅游人才培养游研究文献中以社科基础研究和社科行业指导为主, 总计占比 $66.4 \%$, 而社科政策研究、社科职业指导、高中等教育等其他研究的比例少。

2.2.2.3 文献分布

通过分析发表的所有相关文献分布发现，学术论文数目文献及报刊分布依次排名为:《旅 游纵览》（28）, 《中国旅游报》（18）, 《中国商贸》（5）现代商贸工业（5），特区经济 (5), 长春师范学院学报 (5), 改革与开放 (5), 此外还有南昌大学、云南大学和燕山大 
学的硕博士论文 21 篇。从数据显示中可以发现, 该研究内容主要分布在一些普通期刊中, 并 且分布零散论文数量少，核心期刊和中文社会科学类期刊（CSSCI）都处于空白状态。

\subsubsection{4 研究机构}

通过列表可知, 对于智慧旅游视阈下人才培养的研究机构排名前三的分别是辽宁师范大 学（15）、洛阳师范大学（14）、吉林师范大学（10）、桂林理工大学（10）, 以及剩下的 前十的研究机构均为高校, 从中可以得出, 研究机构与研究论题的相关性较强, 由于是旅游 人才培养方面的研究, 所以以师范类大学为主。

2.2.2.5 硕博士论文

在统计该研究方向的硕博士论文排名中，排名前三的是南昌大学（9）、云南大学（6）、 燕山大学 (6), 剩下的前十的大学发表的论文数均为 4 篇。但必须提出说明的是, 所有的这 些硕博士论文中, 博士论文 0 篇, 并且真正以智慧旅游人才培养为论题进行专题研究的只有 1 篇, 其余的硕士论文都只是以研究智慧旅游其他方面研究为主, 只是在文章中提到智慧旅游 发展与旅游人才的培养和打造。

\subsubsection{6 热点研究领域}

通过关键词的识别, 智慧旅游人才培养方面的文献中关键词排名分别是: 智慧旅游 (132)、 人才培养 (39) 、智慧城市（34）、旅游管理（33）、旅游业（28）、旅游管理专业（24）、 对策（21）、旅游产业（19）、乡村旅游（18）、旅游专业（18）。从这些关键词出现的次 数可以知道, 智慧旅游视阈下人才培养方面的研究主要在集中在旅游院校或旅游专业中探讨 如何培养优秀的管理和从业人员，并且以对策研究为主。

\section{3. 智慧旅游人才培养研究的主要内容}

\section{1 培养模式研究}

通过搜索智慧旅游人才培养方面的研究发现, 首先以旅游专业人才培养模式方面的研 究为主, 约占整个相关文献的 $60 \%-70 \%$ 。并且又以定性分析为主, 如左晓娟提出 “智慧旅 游” 大发展趋势下旅游管理专业的人才培养模式应该从学科建设、课程体系、实习基地及 校企合作几方面进行变革与创新 ${ }^{[1]}$, 胡晓聪提出 “互联网+” 背景下旅游人才培养的新模 式主要从课程建设与拓展、师资队伍建设、智慧旅游体验中心建设和校企合作深化四个方 面来着手建设。 ${ }^{[2]}$ 严伟课题组提出了 “一化三型” 的旅游管理人才培养模式, 即对于旅游 管理人才培养应转化为具体的、可操作的人才培养模式, 将 “行业化” 的人才培养理念落 实到 “复合型”、“职业性”、“创业型”三型人才培养的全过程和全要素中。 ${ }^{[3]}$ 刘亦雪 提出智慧旅游视角下旅游管理专业 $O P E C$ 人才培养模式, 即以目标导向培养 (0) 为依据, 人才专业性培养 (P) 的三种课程模式和人才创新性培养 (E) 的两种具体培养方式为主, 并综合运用挂职锻炼方式进行人才实践能力（C）培养。

大多数的学者都提出在智慧旅游背景下旅游专任人才培养的模式主要是从培养目标、 课程体系、教学方式、校企合作等几个方面来改进 ${ }^{[5-7]}$, 此外, 也有部分学者进行个案研 究, 如一些学者分别从厦门、秦皇岛、泰安、湖南等研究地区的旅游人才培养的现状及问 题出发, 提出该地区智慧旅游人才培养的模式, 但基本策略还是从政府投入、课程体系、 校企合作、师资队伍等几个方面进行创新建设 ${ }^{[8-10]}$ 。

\section{2 课程改革研究}

对于具体课程体系教学改革内容方面, 也是目前学者在这方面相对研究较多的领域, 如杨华提出智慧旅游时代旅游专业课堂教学新方法, 主要包括实验操作法、任务驱动法、 自主学习法和读书指导法。 ${ }^{[11]}$ 张萌指出为适应智慧旅游发展, 旅游管理专业 “三措并举” 的改革的创新思路, 从计划准备、操作实施, 到结果评价, 实施有步骤地三个措施, 复合 地突出了专业培养特色, 强了科学实践, 从而提高教学质量。 ${ }^{[12]}$ 孙丽坤, 魏晓鸣基于目前 
旅游管理专业本科教育的问题出发, 提出构建完善旅游专业本科课程体系, 应从整合专业 核心课程、增加管理信息公共课及与企业共同合作育人的思路深层发展。 ${ }^{[13]}$ 张永波以旅游 类院校为例, 根据职业教育和旅游业态发展特点, 围绕培养学生的职素养和实践能力, 结 合旅游职业院校教育信息化建设的实践，从行业接轨、专业融合、教学服务等方面来考察 研究信息化环境下的人才培养模式改革, 阐述了融合行业的职业教育信息化建设思路。

\section{3 校企合作研究}

在校企合作方面, 首先大多数的学者从总体上把握智慧旅游人才培养模式中都提出了 创新的校企合作理念，包括校企共同开发课程、共同育人的教育模式。其次个别学者针对 智慧旅游背景下校企合作具体模式也提出了不同的校企合作观点, 如彭雯指出智慧旅游背 景下高职院校旅游专业人才培养新要求是专业型人才+复合型人才, 在专业课程设置、实 训基地、教师团队方面应充分发挥企业合作优势, 多元打造, 拓宽实习方向, 从而与企业 共同培养优秀人才。 ${ }^{[15]}$ 曹俊华分析了高职旅游院校校企合作存在的因缺乏积极沟通和交流 而导致人才培养需求不匹配的问题，提出 “智慧旅游” 背景下高职旅游院校校企合作的思 考保持密切联系和随时交流, 通过合作办学、订单培养、选派行业能手到校兼教等多种合 作方式来培养企业所需的旅游人才, 并且旅游各相关主体应建立智慧旅游人才培养合作联 动机制。

\section{4 其他方面研究}

在智慧旅游视阈下，旅游专业人才培养除了培养模式、课程教学改革、校企合作方面 的研究较多外, 还包括一些旅游人才具体的培养过程研究, 如创新创业及就业能力研究: 刘丽群、何海提出智慧旅游发展大背景下, 旅游院校人才培养应与产业发展紧密结合, 共 同协作从而更科学地引导大学生创业、择业、就业, 并为学生的创新创业提供实践的条件 和机会, 鼓励学生根据智慧旅游的市场需求选择合适的项目自主创业, 并为学生提供技术 指导和资金支持，营造创新创业的文化氛围。 ${ }^{[18]}$ 肖来通过对各大旅游企业和高职旅游毕业 生进行相关调研, 了解旅游企业对人才需求的变化和学生的就业现状, 高职院校旅游类专 业应当适时调整培养方案, 从基础能力、职业技能、职业发展能力三大模块 12 类子课程中 重构专业学生的就业核心能力, 以适应市场的需求, 提高学生就业质量。 ${ }^{[19]}$ 此外, 也有部 分学者专门从事智慧旅游背景下对专业人才的影响及需求做出分析, 如魏九峰指出智慧旅 游背景下, 旅游业发展对应用型本科旅游管理专业人才培养提出了新的需求就是需要智慧 旅游人才、专业技能人才和强综合能力的应用型人才。 ${ }^{[20]}$ 郭珊珊也指出智慧旅游条件下, 新型旅游人才的培养应该注重培养创新意识、精湛技术和高技能, 并且同时要注重学生全 面发展、综合素养的提高。

\section{4. 智慧旅游人才培养研究的主要特点}

\section{1 研究深度不够}

通过整理可以发现, 智慧旅游人才培养方面的研究内容比较广泛, 但主要集中在大的 旅游专业或旅游人才的培养模式的探索上, 缺少具体的培养过程或培养细节的研究, 研究 深度不够, 虽然也有部分文献是进行课程体系及校企合作等细节研究, 但研究的成果依旧 比较概念化, 较少具有实际指导意义的措施, 应更关注人才在培养过程中各个细节, 深入 挖掘, 提出具有参考意义的意见。

\section{2 研究方法单一}

通过整理智慧旅游人才培养方面的文献发现, 大多数文献在研究方法中是以文献分析加 经验总结的方式为主, 缺少定量分析和个案分析, 研究方法较为传统单一。 


\section{3 研究主体局限}

在整理的文献中，几乎所有涉及的文献都是从旅游院校或旅游专业的角度来思考智慧 旅游人才的培养模式和培养方法, 几乎没有文献是探讨旅游行业和企业是如何培养和培训 智慧旅游人才, 而实际情况是对于目前正在从事旅游行业进行旅游工作的人员更应该及时 把握行业的发展新变化, 加强学习、加强培训去适应新的旅游需求。

\section{5. 智慧旅游人才培养研究展望}

\section{1 加强理论研究, 深挖培养细节}

智慧旅游人才培养涉及到旅游学、教育学、管理学、经济学、理工学等各类综合科学, 应多借鉴这些学科的跨学科研究方法, 借鉴国内外优秀的智慧旅游人才培养的相关理论和经 验, 构建智慧旅游人才培养的研究理论体系, 同时关注培养细节和培养过程, 深入研究。

\section{2 丰富研究方法}

在研究方法中，除了传统的文献分析和经验总结外，更应该关注定量分析和个案分析的 研究方法, 通过对问卷调查和实地走访等形式了解各类旅游企业在智慧旅游发展环境下人才 的真正需求情况, 并对国内外成功的智慧旅游人才培养的院校及行业进行调查分析, 总结具 有指导性意义的经验方法, 丰富研究方法。

\section{3 拓宽研究思路}

对于研究主体中，除了考虑旅游院校对旅游专业的人才培养，也应该关注旅游行业中目 前正在从事旅游行业的工作人员如何进行智慧旅游的学习和培训, 甚至可以从不同的旅游行 业类型出发来研究旅游从业人员的培养, 并且在院校人才培养中, 除了旅游专业人才外, 涉 及到智慧信息技术的计算机人才、电子商务人才都是未来的智慧旅游人才, 都可以作为研究 对象。

\section{6. 结束语}

智慧旅游人才的培养是智慧旅游全面发展的关键, 我们应该更加关注智慧旅游人才的 培养和打造。通过分析可以知道我国智慧旅游人才培养的研究单一零散、缺乏系统性, 且 研究内容重复粗浅, 今后的研究更应该注重体系研究, 形成智慧旅游人才培养的理论框架 和方法论的体系, 同时丰富研究方法, 多运用定量分析和个案分析, 并且从个案的实际情 况实际特点结合指出具体的人才培养措施, 对于院校和行业都应考虑在内, 拓宽研究视角, 强化企业视角的研究力度。

\section{References}

[1] Zuo Xiaojuan, Yu Yong, an innovative study on the training model of tourism management professionals under the trend of "Intelligent Tourism" [J]. Journal of Taiyuan City Vocational College, 2016, 03 (4): 137- 138.

[2] Hu Xiaocong. On the training mode of tourism talents under the background of" Internet +" [J]. commercial economy, 2015, 10: 70- 71.

[3] Yan Wei. Exploration and practice of training mode of "one and three type" tourism management talents[N]. China Tourism daily, 2017-06-14 (004).

[4] Liu Yi Xue. The innovation of OPEC talents training mode of tourism management major from the perspective of Intelligent tourism . [J]. China's collective economy,2016, 08 (22): 150- 152. 
[5] $\mathrm{Hu}$ Hongmei. Innovation of tourism talents training mode in $\mathrm{E}$ era[J]. Journal of Wuhan Polytechnic. 2016, 04 (15): 44- 47.

[6] Liu Yingying. Study on the training of tourism talents in Colleges and Universities -- Based on the perspective of " Intelligent tourism" [J].Journal of Sichuan Tourism College, 2014, 04 (113): 78- 80 .

[7] Wei Fengyun. The training of tourism professionals in Universities under the background of Intelligent tourism study [J]. Journal of Changchun Normal University, 2017, 02 (36): 83- 86.

[8] Sun Weifang. Xiamen's "Intelligent Tourism Talents" training study [J]. tourism overview, 2015, 12: $103-104$.

[9] Jiang Lan, Wang Jing, Liu Qiaoyan. Study on the training of compound tourism talents in Qinhuangdao under the Intelligent Tourism [J]. modern communication 2014, 11 (394): 35- 36.

[10] Zhang Ying, Liu Xiaomei. Tai'an tourism talents training based on Intelligent tourism study [J]. education and teaching forum, 2016, 12 (51): 72- $73 .$.

[11] Yang Hua. The development of "Intelligent tourism " and the reform of classroom teaching methods for tourism majors. [J]. tourism overview, 2014,05: 84- 85..

[12] Zhang Meng. Study on the innovation of "three measures" in the practice teaching of Tourism Management Specialty under the background of Intelligent Tourism [J]. Journal of Sichuan Vocational and Technical College, 2016,04: 141- 144.

[13] Sun Likun, Wei Xiaoming. Construction of undergraduate curriculum system of Tourism Management Based on smart tourism background [J]. southern China Journal, 2017,10: 83- 84.

[14] Zhang Yongbo. Exploration and study of education informatization in Higher Vocational Colleges with integration of industries -- Taking Tourism Vocational Colleges as an example. [J]. Software Guide (Education Technology), 2016,01 (01): 76- 77.

[15] Peng Wen. The school enterprise cooperation of Tourism Specialty in Higher Vocational Colleges under the background of "Intelligent tourism ", [J]. enterprise guide, 2015,08: 121.

[16] Cao Junhua. The challenge and thinking of smart tourism for talents training in Higher Vocational Tourism Colleges and Universities[J]. Journal of Hubei Adult Education College, 2015,07: 28-30.

[17] Cao Junhua. Study on the educational mechanism of school enterprise cooperation between Intelligen tourism and Higher Vocational Tourism Colleges [J]. Journal of Anyang Normal University, 2015,04: 147-149.

[18] Liu Liqun, he Hai. Hunan Intelligent Tourism Talents innovative and entrepreneurial ability training way [J]. education observation, 2017,07: 70-73.

[19] Xiao Lai. Study on improving core competitiveness of tourism students in Vocational Colleges under the background of smart Tourism [J]. business economics, 2017,11: 184-186.

[20] Wei Jiufeng. Study on the demand and training mode of Applied Undergraduate Tourism Management Talents under the background of smart Tourism [J]. human resource management, 2015,11: 148-149.

[21] Guo Shanshan. Demand analysis of tourism professionals under the background of "Intelligent tourism ", [J]., Bohai economic outlook, 2017,10: 95-96. 